\title{
Seminario interno de profesores 2008 "De Medellín a Aparecida. Aportes, desafíos, creatividad, originalidad de una iglesia particular"
}

El seminario interno de profesores de la Facultad de Teología tuvo lugar entre los meses de abril y noviembre del año 2008. El tema escogido fue: "De Medellín a Aparecida. Aportes, desafíos, creatividad, originalidad de una iglesia particular".

Se eligió esta temática dado que en el año 2008 se cumplieron cuarenta años de la II Conferencia General del Episcopado Latinoamericano llevada a cabo en la ciudad colombiana de Medellín.

Cuarenta años permiten tener una cierta perspectiva para evaluar los frutos de un acontecimiento. En este caso se juzgó adecuado hacer un balance de dicha Conferencia que incluyera sus antecedentes, su contenido, sus logros en el tiempo y los desafíos de cara al futuro para la Iglesia en América Latina.

Teniendo en cuenta estos presupuestos, el Seminario se inició con la presentación del pensamiento de Mons. M. Larraín, quien tuvo una importante labor en la creación de CELAM. El análisis de su pensamiento, especialmente su diagnóstico de la situación latinoamericana y el papel de la Iglesia en aquel momento. El prof. Fernando Berríos abordó este tema en su ponencia "Mons. Manuel Larraín y la conciencia eclesial latinoamericana. Visión y legado de un precursor".

Desde la primera sesión del seminario se percibió que había temas especialmente relevantes en la teología latinoamericana que merecían una mayor reflexión y discernimiento: ¿qué es la libertad?, ¿qué significa que los pobres sean un lugar teológico?

Ampliando esta parte introductoria del seminario, el prof. Patricio Miranda presentó en su ponencia el "Desarrollo de la Doctrina Social de la Iglesia, en el mundo previo al Vaticano II, y luego, entre Medellín y Aparecida. Cuestionamiento y reposicionamiento de un tema teológico con repercusión sociopolítica. Status actual y posible futuro". La discusión se centró en torno a la relación entre lo dado y lo producido respecto a la DSI, tema que ha sido ampliamente reflexionado en la teología latinoamericana. Se constató el peligro de naturalizar un orden social determinado, pero también de naturalizar una determinada forma de comprender la realidad. Reapareció así el tradicional problema de la relación entre principios y realidad, o más aún, de la relación entre pensar y ser, nudo gordiano de toda filosofía.

Las ciencias sociales tuvieron una influencia significativa en Medellín, la cual continuó en las sucesivas Conferencias del Episcopado Latinoamericano; en consecuencia, se juzgó de interés analizar las características de la influencia de estas ciencias en las distintas Conferencias. Esta tarea estuvo a cargo del prof. Pedro Morandé con la ponencia "Cambios en la interpretación de lo acontecido en América Latina y en la identidad latinoamericana entre 1968 y 2007, particularmente en la reflexión teórica de las ciencias sociales, que han influido en la reflexión Episcopal Latinoamericana decantada en las cinco Conferencias Episcopales". La pregunta principal que surgió estuvo referida a la capacidad del hombre de interpretar auténticamente la realidad; y 
en caso de estar correctamente interpretada; ¿cuál es su capacidad de transformarla?, ¿es posible, y en qué medida?

La ponencia siguiente analizó específicamente el Documento de Medellín mostrando la relación entre éste y el Concilio Vaticano II. El prof. Fernando Retamal tituló su ponencia: "Medellín como recepción latinoamericana del Vaticano II, y particularmente LG, GS, NAe: gestación, desarrollo, originalidades de una Conferencia Episcopal fundante". Incorporando lo visto en las sesiones anteriores, la discusión agregó el importante tema de la recepción como acontecimiento vital que nace desde el sensus fidei-fidelium. Si anteriormente se tenía la necesidad irrenunciable de transformar la realidad con su correlato hermenéutico de una correcta lectura de la misma realidad, esto supondrá no solamente una adecuada instrumentalidad de las ciencias sociales, sino también una lectura desde la fe vivida, esto es, la Tradición, entendida en sus aspectos diacrónicos y sincrónicos.

La temática de los signos de los tiempos estuvo muy presente en Medellín y se fue enriqueciendo en los años siguientes. El prof. Eduardo Silva presentó esta problemática en la ponencia "Una teología de los signos de los tiempos latinoamericanos. Validez, límites y porvenir de una hermenéutica teológica del Concilio Vaticano II". La presentación abrió la discusión al cómo Dios se hace presente en el "otro" y sale a mi encuentro. Se hace, entonces, necesario integrar en la teología las polaridades: tiempo-eternidad, particular-universal, el mismo-lo mismo. Si se trata de un encuentro con Dios desde lo particular, no se pierde ni lo uno ni lo otro: Dios y la creatura.

Medellín constituyó, también, un momento importante para la reflexión filosófica latinoamericana y su desarrollo posterior. Este aspecto fue tratado por el prof. Juan Carlos Scannone en la ponencia "Filosofía de la liberación. Historia, características, vigencia actual”. La gran pregunta que envolvió la discusión en esta sesión fue la siguiente: Si la filosofía latinoamericana, que quiere ser situada y con apoyo en las ciencias sociales, ¿puede pretender ser auténticamente filosofía, es decir, razón universal?

La II Conferencia del Episcopado Latinoamericano fue un hito importante para la reflexión bíblica en América Latina. El prof. Miguel Ángel Ferrando expuso "La interpretación de la Biblia en la Teología de la Liberación, 1971-1984", constatando falencias importantes, al menos en su etapa inicial, en torno a la relación entre interpretación bíblica y transformación social.

El diálogo entre literatura y teología en estas últimas décadas ha sido algo muy propio de América Latina. Le correspondió al prof. Alberto Toutin abordar el hecho de que "La realidad crucial de los pobres da que pensar a la teología latinoamericana. Teología y literatura desde esta ladera del mundo". La literatura ha sido por generaciones una forma privilegiada de reflexión, también teológica, en Latinoamérica. No es de extrañar que en este último medio siglo la literatura haya apoyado las nuevas corrientes de pensamiento teológico.

La Conferencia de Medellín contribuyó significativamente a un desarrollo teológico propio en América Latina. Este proceso fue analizado por el prof. Sergio Silva en su ponencia "La teología de la liberación". Los rasgos característicos que se destacaron más fue que la Teología de la Liberación es una teología que ha permitido la entrada del "otro" a la reflexión teológica: llámese pobre, cambio, praxis. Es en el fondo la posibilidad de que lo "profano" diga una palabra sobre Dios. De ahí que la 
TL sea sobre todo una reflexión y lugar hermenéutico desde el cual ver a Dios actuando. Esta es su riqueza y también su límite. La discusión se abrió posteriormente a una segunda cuestión que había venido sutilmente debatiéndose: la TL supone que el Dios Trascendente actúa en la inmanencia. Esto es básico en la fe cristiana. Sin embargo, hoy en día no puede suponerse sin más aceptado y explicado con facilidad en un mundo, en cierto modo, nuevamente dualista, tal vez panteísta-no creyente. El mesianismo y el Dios Creador no son datos supuestos en un mundo no creyente. Si la teología no se hace cargo de ellos, en el fondo, acepta y apoya la tesis inmanentista.

Los aspectos eclesiológicos han sido un tema siempre presente en el quehacer teológico y pastoral de América Latina. El prof. Rodrigo Polanco presentó lo más característico del desarrollo eclesiológico en Latinoamérica, haciendo un balance desde la eclesiología del Concilio Vaticano II. Su ponencia se tituló: "Eclesiología en Latinoamérica. Exposición y balance crítico". Los resultados apuntaron a que las intuiciones y temas puestos por la TL siguen siendo válidos y requieren de ulterior reflexión, y han sido un aporte a la vida eclesial. Pero no así su intento sistemáticoeclesiológico, que se aleja de lo propuesto por el Concilio Vaticano II, como norma segura de comprensión eclesiológica.

La Conferencia de Medellín fue el punto de partida para la reflexión de una forma de creencia y vida eclesial latinoamericana. Se trata de la religiosidad popular. Esta manifestación fue abordada por los profesores Guillermo Rosas y Cristian Johansson. El trabajo mostraba la gestación de un desarrollo enriquecedor entre teología y religiosidad popular y la progresiva incorporación de este tema en los documentos magisteriales.

El seminario concluyó con la ponencia del prof. Juan Noemi quien analizó un aspecto siempre presente en el pensar teológico de América Latina. Se trata del tema "Mundo e iglesia. Esperanza en una comunión católica". Articuló los temas de todo el seminario y mostró cómo la relación Iglesia-mundo es una relación de interpenetración, en donde tanto la Iglesia como el mundo se influyen y se necesitan mutuamente.

Durante este medio siglo, en Latinoamérica se ha ido gestando un quehacer teológico. Ha habido muchos errores, es cierto, pero se ha hecho algo que es más importante: pensar la fe, querer hacerla relevante para el hombre y mujer latinoamericanos. Hacer teología. Una Iglesia que no piensa, una fe que no se nutre de la teología, no sobrevive.

Se publican en este número de Teología y Vida varias de las ponencias de este seminario por medio del cual la Facultad de Teología quiso reflexionar en este cuadragésimo aniversario, sobre la Conferencia de Medellín que tan significativamente orientó el caminar de la Iglesia en América Latina en estas últimas cuatro décadas.

Rodrigo Polanco

Cristian Johansson 